\title{
Hydrogen sulfide suppresses the expression of MMP-8, MMP-13, and TIMP-1 in left ventricles of rats with cardiac volume overload
}

\author{
Chao-ying ZHANG ${ }^{1}$, Xiao-hui $\mathrm{LI}^{1, *}$, Ting $\mathrm{ZHANG}^{2}$, Jin $\mathrm{FU}^{3}$, Xiao-dai CUI ${ }^{3}$ \\ ${ }^{1}$ Department of Cardiovascular Diseases, Children's Hospital Affiliated to Capital Institute of Pediatrics, Beijing 100020, China; \\ ${ }^{2}$ Central Laboratory of Infection and Immunity, Capital Institute of Pediatrics, Beijing 100020, China; ${ }^{3}$ Central Laboratory for Clinical \\ Research, Children's Hospital Affiliated to Capital Institute of Pediatrics, Beijing 100020, China
}

Aim: To study the effects of hydrogen sulfide $\left(\mathrm{H}_{2} \mathrm{~S}\right)$ on the left ventricular expression of MMP-8, MMP-13, and TIMP-1 in a rat model of congenital heart disease.

Methods: Male SD rats underwent abdominal aorta-inferior vena cava shunt operation. $\mathrm{H}_{2} \mathrm{~S}$ donor $\mathrm{NaHS}\left(56 \mu \mathrm{mol} \cdot \mathrm{kg}^{-1} \cdot \mathrm{d}^{-1}\right.$, ip) was injected from the next day for 8 weeks. At 8 weeks, the hemodynamic parameters, including the left ventricular systolic pressure (LVSP), the left ventricular peak rate of contraction and relaxation ( $\left.\mathrm{LV} \pm \mathrm{d} p / \mathrm{d} t_{\max }\right)$ and the left ventricular end diastolic pressure (LVEDP) were measured. The left ventricular tissues were dissected out, and hydroxyproline and collagen I contents were detected with ELISA. The expression of MMP-8, MMP-13, and a tissue inhibitor of metalloproteinase-1 (TIMP-1) in the tissues was measured using real-time PCR, Western blotting, and immunohistochemistry, respectively.

Results: The shunt operation markedly reduced LVSP and LV $\pm \mathrm{d} p / \mathrm{d} t_{\max }$, increased LVEDP, hydroxyproline and collagen I contents, as well as the mRNA and protein levels of MMP-8, MMP-13, and TIMP-1 in the left ventricles. Chronic treatment of the shunt operation rats with NaHS effectively prevented the abnormalities in the hemodynamic parameters, hydroxyproline and collagen I contents, and the mRNA and protein levels of MMP-13 and TIMP-1 in the left ventricles. NaHS also prevented the increase of MMP-8 protein expression, but did not affect the increase of MRNA level of MMP-8 in the shunt operation rats.

Conclusion: $\mathrm{H}_{2} \mathrm{~S}$ suppresses protein and mRNA expression of MMP-8, MMP-13, and TIMP-1 in rats with cardiac volume overload, which may be contributed to the amelioration of ventricular structural remodeling and cardiac function.

Keywords: congenital heart disease; cardiac volume overload; hydrogen sulfide; MMP-8; MMP-13; tissue inhibitor of metalloproteinase 1; hydroxyproline; collagen I; ventricular remodeling

Acta Pharmacologica Sinica (2013) 34: 1301-1309; doi: 10.1038/aps.2013.84; published online 26 Aug 2013

\section{Introduction}

Congenital heart disease (CHD) is the most common cardiovascular disease of childhood. Left-to-right shunt CHD results in an increase in cardiac volume load. Sustained volume overload induces cardiac hypertrophy and ventricular remodeling, eventually leading to decreased cardiac function, which results in chronic heart failure $(\mathrm{CHF})^{[1]}$. $\mathrm{CHF}$ is a serious problem for the health of children; however, its pathogenesis is still unclear.

Hydrogen sulfide $\left(\mathrm{H}_{2} \mathrm{~S}\right)$ is a newly discovered gasotransmitter in the cardiovascular system. The four most important mammalian enzymes that synthesize $\mathrm{H}_{2} \mathrm{~S}$ are cystathionine- $\beta$ -

\footnotetext{
* To whom correspondence should be addressed.

E-mail Ixhmaggie@126.com

Received 2012-12-02 Accepted 2013-05-22
}

synthase (CBS), cystathionine- $\gamma$-lyase (cystathionase, CSE) and cysteine aminotransferase (CAT) in conjunction with 3-mercaptopyruvate sulfurtransferase (3-MST). CSE is the main $\mathrm{H}_{2} \mathrm{~S}$-generating enzyme in the cardiovascular system, whereas CBS is the predominant $\mathrm{H}_{2} \mathrm{~S}$ synthase in the brain and nervous system. $\mathrm{H}_{2} \mathrm{~S}$ is synthesized from the sulfur-containing amino acid L-cysteine by either CBS or CSE, both using pyridoxal 5'-phosphate as a cofactor. Along with CAT, 3-MST produces $\mathrm{H}_{2} \mathrm{~S}$ using both L-cysteine and a-ketoglutarate as substrates. Both of these enzymes contribute to $\mathrm{H}_{2} \mathrm{~S}$ formation in the brain and vascular endothelium ${ }^{[2,3]}$.

$\mathrm{H}_{2} \mathrm{~S}$ affects a wide range of physiological and pathological processes in the cardiovascular system and plays an important role in the prevention of coronary heart disease and the development and protection of ischemic myocardial injury ${ }^{[4,5]}$. A clinical observational study has demonstrated that the plasma 
concentration of $\mathrm{H}_{2} \mathrm{~S}$ in patients with CHD is significantly lower than that in normal control subjects, suggesting that decreased plasma $\mathrm{H}_{2} \mathrm{~S}$ levels may correlate with the severity of $\mathrm{CHD}^{[6]}$. Exogenous $\mathrm{H}_{2} \mathrm{~S}$ opens $\mathrm{K}_{\mathrm{ATP}}$ channels to reduce myocardial infarct size $\mathrm{e}^{[7]}$. By inhibiting vascular endothelial cell apoptosis and promoting the regeneration of endothelial cells, $\mathrm{H}_{2} \mathrm{~S}$ has a protective effect on ischemic myocardium ${ }^{[8]}$. Nevertheless, the role of $\mathrm{H}_{2} \mathrm{~S}$ in ventricular structural remodeling is unclear.

Our previous study ${ }^{[9]}$ demonstrated that eight weeks after a left-to-right shunt operation, sodium hydrosulfide (NaHS), an exogenous $\mathrm{H}_{2} \mathrm{~S}$ donor, improved cardiac function and ameliorated cardiac structures. However, the mechanism responsible for these changes is not fully understood. The matrix metalloproteinases (MMPs) are a family of zinc-dependent proteinases that participate in extracellular matrix (ECM) degradation, and contribute to tissue remodeling in a number of disease states. Interstitial collagenases include MMP-1, MMP-8, and MMP-13. MMP-1 cleaves the fibrillar collagens, such as collagen type-I and -III, at specific sites of the collagen molecule ${ }^{[10]}$. MMP-8 has similar specificity to that of MMP-1, but the key feature of MMP-8 is that it is the predominant form of interstitial collagenase found in neutrophils.

Interestingly, it has been reported that MMP-8 was detected in samples taken from end-stage cardiomyopathic disease ${ }^{[11]}$. MMP-13 is the predominant form of interstitial collagenase found in rodents. Using immunoblotting techniques, Spinale et al ${ }^{[12]}$ observed a strong signal for MMP-13 in normal human myocardial samples. Thus, all of the interstitial collagenases have been detected in human LV myocardium. Rodents do not express MMP-1, and MMP-8 is synthesized and released primarily by inflammatory cells. Therefore, the predominant collagenase within the rodent myocardium is MMP- $13^{[13]}$. Tissue inhibitors of metalloproteinases (TIMPs) are specific inhibitors of matrixins that participate in regulating the local activity of MMPs in tissues ${ }^{[10]}$. TIMP-1, which is released by macrophages and connective tissue cells, is widely present in tissues and body fluids and is the inhibitor of most MMPs ${ }^{[14]}$. With TIMP-1 deficiency, myocardial contractility is decreased, resulting in LV enlargement, an increase in areas of scarring, time-dependent reduced myocardial collagen, and extensive ventricular remodeling ${ }^{[15,16]}$. The inhibition of MMPs significantly modifies chronic volume overload-induced myocardial reconstruction, reducing left ventricular hypertrophy, and protecting ventricular function ${ }^{[17]}$.

Recent studies ${ }^{[18-20]}$ have demonstrated that MMP/TIMP changes affect the level of ECM collagen content, and more importantly, the dynamic balance between MMPs and TIMPs to maintain a stable myocardial ECM structure. The present study was designed to analyze the expression of MMP-8, MMP-13, and TIMP-1 in rats with left-to-right shunt leading to volume overload-induced $\mathrm{CHF}$ and to determine the role of $\mathrm{H}_{2} \mathrm{~S}$ in ventricular structural remodeling induced by volume overload.

\section{Materials and methods}

\section{Animal model of left-to-right shunt}

All animal experiments were conducted in accordance with the Guide to the Care and Use of Experimental Animals issued by the Ministry of Health, China. Male Sprague-Dawley rats were provided by the Animal Research Centre of Peking University First Hospital. The rats were housed in plastic cages in a room with a controlled humidity of $40 \%$, a temperature of $22^{\circ} \mathrm{C}$ and 12-h light cycle from 6:00 AM to 6:00 PM.

The rat model was established by an abdominal aorta-inferior vena cava shunt operation as described by Oeampe $e t$ a ${ }^{[21]}$. Briefly, 30 male Sprague-Dawley rats (4 weeks age), weighing 120-140 g, were randomly divided into a sham group $(n=8)$, a shunt group $(n=8)$, a sham $+\mathrm{NaHS}$ group $(n=6)$ and a shunt+NaHS group $(n=8)$. Rats in the shunt and shunt $+\mathrm{NaHS}$ groups were anesthetized with $0.25 \%$ pentobarbital sodium (40 mg/ kg, intraperitoneal injection). The abdominal aorta and inferior vena cava were exposed, and then a bulldog vascular clamp was placed across the aorta caudal to the left renal artery. The aorta was punctured at the union of the segment two-thirds caudal to the renal artery and one-third cephalic to the aortic bifurcation with an 18-gauge disposable needle. The needle was then slowly withdrawn and a 9-0 silk thread was used to stitch the puncture of the abdominal aorta wall.

In the sham and sham+NaHS groups, rats underwent the same experimental protocol as mentioned above, except for the shunt procedure. Beginning on the second day after the sham and shunt surgeries, rats in the shunt $+\mathrm{NaHS}$ and sham $+\mathrm{NaHS}$ groups were injected intraperitoneally with $\mathrm{NaHS}\left(\mathrm{H}_{2} \mathrm{~S}\right.$ donor) at $56 \mu \mathrm{mol} \cdot \mathrm{kg}^{-1} \cdot \mathrm{d}^{-1}$ for 8 weeks as previously described ${ }^{[22]}$, and at the same time, rats in the shunt and sham groups were injected with the same volume of normal saline.

\section{Measurements of hemodynamic parameters}

At 8 weeks after the operation, rats in each group were anesthetized with $25 \%$ urethane, $0.5 \mathrm{~mL} / 100 \mathrm{~g}$ via intraperitoneal injection. After anesthesia, a cannula with a heparinized PP10 in PP50 catheter was inserted into the left ventricle (LV) through the right common carotid artery. The catheter was connected to a pressure transducer. The pressure transducer was connected to a data recording system (BL-420F, Biological Data Acquisition \& Analysis System, Chengdu TME Technology Co, Ltd, China). The hemodynamic parameters, such as LVSP (left ventricular systolic pressure), LVEDP (left ventricular end-diastolic pressure), $\mathrm{LV}+\mathrm{d} p / \mathrm{d} t_{\max }$ (left ventricular peak rate of contraction) and $\mathrm{LV}-\mathrm{d} p / \mathrm{d} t_{\max }$ (left ventricular peak rate of relaxation), were measured as described previously ${ }^{[23]}$.

\section{Estimation of shunt volume}

Eight weeks after surgery, blood samples were collected from the external carotid artery, pulmonary artery, and femoral vein of each rat and analyzed (Gastat-3, Techno Medica, Tokyo, Japan) for blood oxygen saturation. The pulmonaryto-systemic flow ratio (QP/QS) was correspondingly calculated and the left-to-right shunt volume was estimated. 


\section{Hydroxyproline concentration in the left ventricle}

Initially, $50 \mathrm{mg}$ of LV tissue was homogenized on ice in 500 $\mu \mathrm{L}$ normal saline. The supernatant derived from the homogenates were clarified by centrifugation at $12000 \mathrm{r} / \mathrm{min}$ for $10 \mathrm{~min}$ at $4^{\circ} \mathrm{C}$. The hydroxyproline concentration was then determined using a hydroxyproline detection kit (Nanjing Jiancheng Bioengineering Institute, Nanjing, China; Code No A030) according to the manufacturer's instructions.

\section{Measurement of collagen I concentration in the left ventricle}

The supernatant derived from the homogenates was obtained as previous described. Then, the concentration of collagen I in the left ventricle (LV) was measured by enzyme-linked immunosorbent assay (ELISA) (R\&D Systems, Minneapolis, MN, USA; Code No DZE30413 and DZE30458) according to the manufacturer's instructions.

\section{RNA extraction and cDNA synthesis}

Total RNA from frozen ventricular tissue was isolated using a total RNA extraction kit (Tiangen Biotech, Beijing Co, Ltd, China; Code No DP419) according to the manufacturer's protocol and quantified by measuring the absorbance at $260 \mathrm{~nm}$. The quality of the isolated RNA was determined by measuring the 260:280 nm ratio. Thereafter, first-strand cDNA was synthesized using a first-strand cDNA synthesis kit (Tiangen Biotech, Beijing, China, Code No KR104) according to the manufacturer's protocol.

Relative gene expression analysis by real-time polymerase chain reaction (RT-PCR)

PCR primers were designed using commercial software (Beacon Designer, Bio-Rad Laboratories, Hercules, CA, USA) to produce an amplicon length of 75-150 bp. Primers used in the PCR assays are presented in Table 1. RT-PCR was performed with the ABI Prism 7500 System (Applied Biosystems, New York, NY, USA), using the UltraSYBR Green PCR kit (Beijing CoWin Bioscience Co, Ltd, China; Code No CW0956). The thermal cycling conditions consisted of an initial denaturation step at $95^{\circ} \mathrm{C}$ for $10 \mathrm{~min}$ and 40 cycles of $95^{\circ} \mathrm{C}$ for $15 \mathrm{~s}$ and $60^{\circ} \mathrm{C}$ for $60 \mathrm{~s}$. A melting curve was determined at the end of each cycle to confirm the specificity of the primers and the purity of the PCR product.

The results were analyzed using Applied Biosystems 7500

Table 1. Primers used in the present study.

\begin{tabular}{lll}
\hline Gene & & \multicolumn{1}{c}{ Nucleotide sequence } \\
\hline \multirow{2}{*}{ MMP-8 } & Sense & 5'-GAT TCA GAA GAA ACG TGG ACT CAA-3' \\
& Antisense & 5'-CAC CAG GAT CAG TGG AGT GAG A-3' \\
MMP-13 & Sense & 5'-GGG ACG CCC ATT TTG ATG-3' \\
& Antisense & 5'-AGC TCA TGG GCA GCA ACA AT-3' \\
TIMP-1 & Sense & 5'-AGC CCT GCT CAG CAA AAG G-3' \\
& Antisense & 5'-CTG TCC ACA AGC AAT GAC TGT CA-3' \\
GAPDH & Sense & 5'-CAA GGT CAT CCA TGA CAA CTT TG-3' \\
& Antisense & 5'-GGG CCA TCC ACA GTC TTC TG-3' \\
\end{tabular}

Real-Time PCR System Sequence Detection Software ver 1.4 to obtain $C_{\mathrm{T}}$ values, where $C_{\mathrm{T}}$ values are threshold cycles at which a statistically significant increase in the detection of SYBR Green emission intensity occurs. $C_{T}$ values were then normalized to a glyceraldehyde-3-phosphate dehydrogenase (GAPDH) endogenous control to account for variability in RNA concentrations between samples to obtain $\Delta C_{T}$ values. To obtain $\Delta \Delta \mathrm{C}_{\mathrm{T}}$ values, we subtracted the $\Delta \mathrm{C}_{\mathrm{T}}$ value for the control samples from that for the treated samples. Finally, the relative quantification value was calculated as $2^{-\Delta \Delta C T}$.

\section{Western immunoblotting}

Ventricular tissue was lysed in a lysis buffer $(0.2 \mathrm{~mL} 1 \mathrm{~mol} / \mathrm{L}$ Tris-HCl, pH 8.0, $0.3 \mathrm{~mL} 5 \mathrm{~mol} / \mathrm{L} \mathrm{NaCl}, 10 \mu \mathrm{L} 500 \mathrm{mmol} / \mathrm{L}$ ethylenediaminetetraacetic acid, $0.1 \mathrm{~mL} 100 \mathrm{mmol} / \mathrm{L}$ phenylmethanesulfonyl fluoride, and $10 \mu \mathrm{L}$ Triton X-100, with water added to $10 \mathrm{~mL}$ ). The extracts were clarified by centrifugation at $12000 \mathrm{r} / \mathrm{min}$ for $15 \mathrm{~min}$ at $4{ }^{\circ} \mathrm{C}$. Protein concentration was determined with the $\mathrm{BCA}^{\mathrm{TM}}$ protein assay kit (Thermo Fisher Scientific Inc, Waltham, MA, USA). Equal amounts of total protein $(60 \mu \mathrm{g})$ were resolved by sodium dodecyl sulfatepolyacrylamide gel electrophoresis (SDS-PAGE) on a 15\% gel and transferred to a polyvinylidene difluoride (PVDF) membrane (GE Healthcare UK Limited, Buckinghamshire, UK). The membrane was blocked with $5 \%(w / v)$ fat-free milk in TBST $[0.05 \%(v / v)$ Tween in TBST] at room temperature for $1 \mathrm{~h}$, and then probed with rabbit polyclonal antibodies (Santa Cruz Biotechnology, Santa Cruz, CA, USA) against MMP-8, MMP-13, and TIMP-1 at a 1:500 dilution overnight at $4{ }^{\circ} \mathrm{C}$. The membrane was then probed with horseradish peroxidase conjugated goat anti-rabbit IgG (1:2500, Santa Cruz Biotechnology) for $2 \mathrm{~h}$ at room temperature. The reactions were developed with enhanced chemiluminescence reagents (Beijing TransGen Biotech Co, Ltd, Beijing, China) and the images were obtained by exposure to X-ray films (Kodak Scientific Imaging film, Rochester, NY, USA). The films were digitized with Bio-Rad Gel Doc XR (Bio-Rad Laboratories, Hercules, CA, USA) and quantified with Quantity One software (Bio-Rad Laboratories, Hercules, CA, USA). GAPDH blots were used as a loading control. The bands were normalized with GAPDH controls.

\section{Immunohistochemistry}

For immunohistochemistry, LV preparations were cut to a thickness of $5 \mu \mathrm{m}$, deparaffinized with xylene, rehydrated with graded ethanol and washed in water. These sections were boiled in a microwave for $15 \mathrm{~min}$ for antigen retrieval. They were then treated with $3 \%$ hydrogen peroxide $\left(\mathrm{H}_{2} \mathrm{O}_{2}\right)$ for $15 \mathrm{~min}$ at room temperature to block endogenous peroxidase. Tissue sections were incubated with rabbit polyclonal antibodies against MMP-8, MMP-13, and TIMP-1, respectively (1:50, Beijing Biosynthesis Biotech Co, Ltd, China), for $90 \mathrm{~min}$ at room temperature. Thereafter, sections were washed three times with phosphate-buffered saline (PBS) and incubated for 50 min with a secondary antibody (Quanhui Imp \& Exp Int'1 Co, Ltd, Macao, China). Positive reactions were visualized 
with 3,3'-diaminobenzidine. Peroxidase-labeled specimens were observed under an AX-80 microscope (Olympus Optical Co, Ltd, Tokyo, Japan). Using an automatic image analysis system for immunohistochemical analysis, with $10 \times 40$ magnification, three fields were randomly selected in each slice for image analysis to measure the average integral optical density (IOD), from which the mean values were calculated.

\section{Measurement of neutrophil infiltration of the LV}

The total number of neutrophils infiltrating the cardiac tissue was assessed quantitatively by counting the number of neutrophils in 40 high-power fields.

\section{Statistical analysis}

Data are expressed as the mean \pm standard error of the mean (SEM) and were analyzed by SPSS (Statistical Package for the Social Sciences) 16.0 software (SPSS Inc, Chicago, IL, USA). For homogeneity of variance values, comparisons among groups were performed with one-way analysis of variance (ANOVA) followed by the least significant difference test. For some heterogeneity of variance values, comparisons among groups were performed with one-way ANOVA followed by Tamhane's T2 test. A value of $P<0.05$ was considered statistically significant.

\section{Results}

\section{LV hemodynamic parameters}

Eight weeks after surgery, compared with the sham group, the shunt group showed significantly increased LVEDP $(24 \pm 7$ $\mathrm{mmHg}$ os $14 \pm 5 \mathrm{mmHg} ; 1 \mathrm{mmHg}=0.133 \mathrm{kPa}, P<0.05)$, and significantly decreased LVSP and LV $\pm \mathrm{d} p / \mathrm{d} t_{\max }(101 \pm 19 \mathrm{mmHg}$ vs $145 \pm 26 \mathrm{mmHg} ; 3768 \pm 321 \mathrm{mmHg} / \mathrm{s}$ vs $5768 \pm 432 \mathrm{mmHg} / \mathrm{s}$; $3219 \pm 219 \mathrm{mmHg} / \mathrm{s}$ vs $5312 \pm 418 \mathrm{mmHg} / \mathrm{s}$, all $P<0.05)$. In addition, compared with the shunt group, the shunt $+\mathrm{NaHS}$ group showed significantly decreased LVEDP $(19 \pm 6 \mathrm{mmHg}$ vs $24 \pm 7 \mathrm{mmHg}, P<0.05)$, and significantly increased LVSP and $\mathrm{LV} \pm \mathrm{d} p / \mathrm{d} t_{\max }(121 \pm 16 \mathrm{mmHg}$ vs $101 \pm 19 \mathrm{mmHg}$; $4865 \pm 254$ $\mathrm{mmHg} / \mathrm{s}$ vs $3768 \pm 321 \mathrm{mmHg} / \mathrm{s} ; 4138 \pm 207 \mathrm{mmHg} / \mathrm{s}$ vs $3219 \pm 219 \mathrm{mmHg} / \mathrm{s}$, all $P<0.05)$. There was no significant difference between the sham and the sham $+\mathrm{NaHS}$ groups (Figure $1)$.

\section{Shunt volume}

The shunt and shunt+NaHS groups showed significantly increased Qp/Qs values compared with the sham and sham $+\mathrm{NaHS}$ groups $(2.14 \pm 0.29,2.07 \pm 0.21$ vs $0.97 \pm 0.21$, $0.90 \pm 0.21$, all $P<0.01$ ). The shunt group was similar to the shunt+NaHS group $(P>0.05)$.

\section{Hydroxyproline concentration in the LV}

Eight weeks after surgery, the concentration of hydroxyproline increased significantly in the shunt group compared with the sham group $(P<0.05)$. The concentration of hydroxyproline decreased significantly in the shunt $+\mathrm{NaHS}$ group compared to the shunt group $(P<0.05)$ (Table 2$)$.
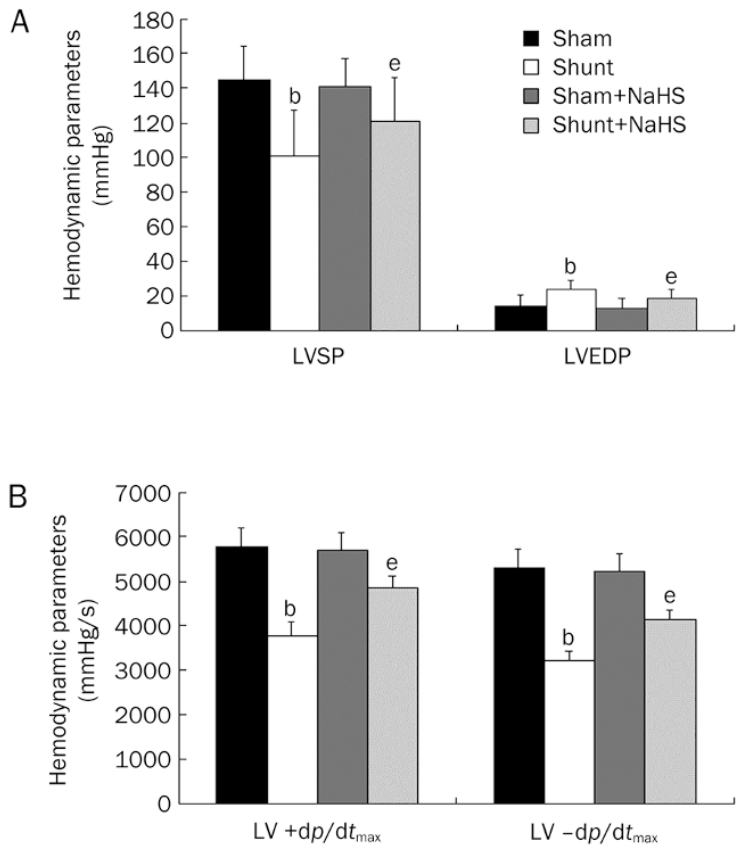

Figure 1. Hemodynamic parameters of rats in four groups. Mean $\pm S E M$. $n=6-8$. ${ }^{\mathrm{b}} P<0.05$ versus the sham group. ${ }^{\mathrm{e}} P<0.05$ versus the shunt group. LVSP, left ventricular systolic pressure; LVEDP, left ventricular enddiastolic pressure; $\mathrm{LV} \pm \mathrm{d} p / \mathrm{d} t_{\max }$, left ventricular peak rate of contraction and relaxation developed pressure; NaHS, sodium hydrosulfide.

Table 2. Hydroxyproline and collagen I content in the left ventricule. Mean \pm SEM. ${ }^{\mathrm{b}} P<0.05$ compared with the sham group. ${ }^{\mathrm{e}} P<0.05,{ }^{\mathrm{f}} P<0.01$ compared with the shunt group; NaHS, sodium hydrosulfide.

\begin{tabular}{lccc}
\hline \multicolumn{1}{c}{ Group } & $n$ & $\begin{array}{c}\text { Hydroxyproline } \\
(\mu \mathrm{g} / \mathrm{mg})\end{array}$ & $\begin{array}{c}\text { Collagen I } \\
(\mu \mathrm{g} / \mathrm{L})\end{array}$ \\
\hline Sham & 8 & $0.21 \pm 0.02$ & $2.13 \pm 0.04$ \\
Shunt & 8 & $0.26 \pm 0.01^{\mathrm{b}}$ & $2.65 \pm 0.12^{\mathrm{b}}$ \\
Sham+NaHS & 6 & $0.21 \pm 0.01$ & $1.94 \pm 0.15$ \\
Shunt+NaHS & 8 & $0.22 \pm 0.02^{\mathrm{e}}$ & $1.67 \pm 0.13^{\mathrm{f}}$ \\
\hline
\end{tabular}

\section{Concentration of collagen I in the LV}

Eight weeks after surgery, compared with the sham group, the concentration of collagen I increased significantly in the shunt group $(P<0.05)$. The concentration of collagen I significantly decreased in the shunt+NaHS group compared to the shunt group $(P<0.01)$ (Table 2$)$.

\section{MMP-8, MMP-13, and TIMP-1 mRNA expression in the LV}

Eight weeks after surgery, the shunt group had significantly increased MMP-8, TIMP-1 (both $P<0.05$ ) and MMP-13 mRNA expression $(P<0.01)$, and the ratio of MMP-13/TIMP-1 was significantly increased $(P<0.01)$ compared to the sham group. The shunt $+\mathrm{NaHS}$ group had significantly decreased MMP-13 $(P<0.01)$, and TIMP-1 $(P<0.05)$ mRNA expression and the ratio of MMP-13/TIMP-1 $(P<0.05)$ compared to the shunt group. 
There were no significant differences in MMP-13, and TIMP-1 mRNA expression between the sham and the sham+NaHS groups (Table 3).

MMP-8, MMP-13, and TIMP-1 protein expression in the LV by Western blotting

Eight weeks after surgery, protein expression of MMP-8, MMP-13, and TIMP-1, and the ratios of MMP-8/TIMP-1 and MMP-13/TIMP-1 were significantly increased in the shunt group compared to the sham operation group $(1.33 \pm 0.14$ vs $0.86 \pm 0.13,1.89 \pm 0.22$ vs $0.93 \pm 0.26, P<0.01 ; 1.04 \pm 0.15$ vs $0.65 \pm 0.12$, $P<0.05 ; 1.96 \pm 0.32$ vs $1.06 \pm 0.09,1.85 \pm 0.08$ vs $1.06 \pm 0.10, P<0.01)$. Protein expression of MMP-8, TIMP-1, and MMP-13, and the ratio of MMP-8/TIMP-1 were significantly decreased in the shunt+NaHS group compared to the shunt group $(0.44 \pm 0.07$ vs $1.33 \pm 0.14,0.54 \pm 0.08$ vs $1.04 \pm 0.15, P<0.01 ; 1.22 \pm 0.16$ vs $1.89 \pm 0.22$, $P<0.05 ; 0.87 \pm 0.07$ vs $1.95 \pm 0.32, P<0.01)$. There were no significant differences in MMP-8, MMP-13, and TIMP-1 protein expression between the sham and the sham $+\mathrm{NaHS}$ groups (Figure 2).

MMP-8, MMP-13, and TIMP-1 protein expression in the LV by immunohistochemistry

Immunohistochemical staining pictures are displayed in Figure 3. Eight weeks after surgery, protein expression of MMP8, MMP-13, and TIMP-1, and the ratios of MMP-8/TIMP-1 and MMP-13/TIMP-1 were significantly increased in the shunt group to the sham operation group $(0.391 \pm 0.003$ vs $0.250 \pm 0.001$, $P<0.01 ; 0.384 \pm 0.004$ vs $0.256 \pm 0.008,0.330 \pm 0.003$ vs $0.263 \pm 0.005$, $1.101 \pm 0.018$ vs $0.948 \pm 0.013,1.119 \pm 0.014$ vs $0.913 \pm 0.054, P<0.05)$. Protein expression of MMP-8, TIMP-1 and MMP-13, and the ratios of MMP-13/TIMP-1, MMP-8/TIMP-1 were significantly decreased in the shunt+NaHS group compared to the shunt group $(0.239 \pm 0.004$ vs $0.391 \pm 0.003, P<0.01 ; 0.234 \pm 0.001$ vs $0.330 \pm 0.003,0.239 \pm 0.007$ vs $0.384 \pm 0.004,0.784 \pm 0.056$ vs $1.119 \pm 0.014, P<0.05 ; 0.757 \pm 0.047$ os $1.01 \pm 0.018, P<0.01)$. There were no significant differences in MMP-8, MMP-13, and TIMP-1 protein expression between the sham and the sham+NaHS groups (Figure 4A).

\section{Neutrophil accumulation in the LV}

When compared with sham-group rats, the shunt operation caused a significant increase in neutrophil accumulation $(P<0.01)$. These effects were significantly attenuated by NaHS (Figure 4B; $P<0.05$ ).
A
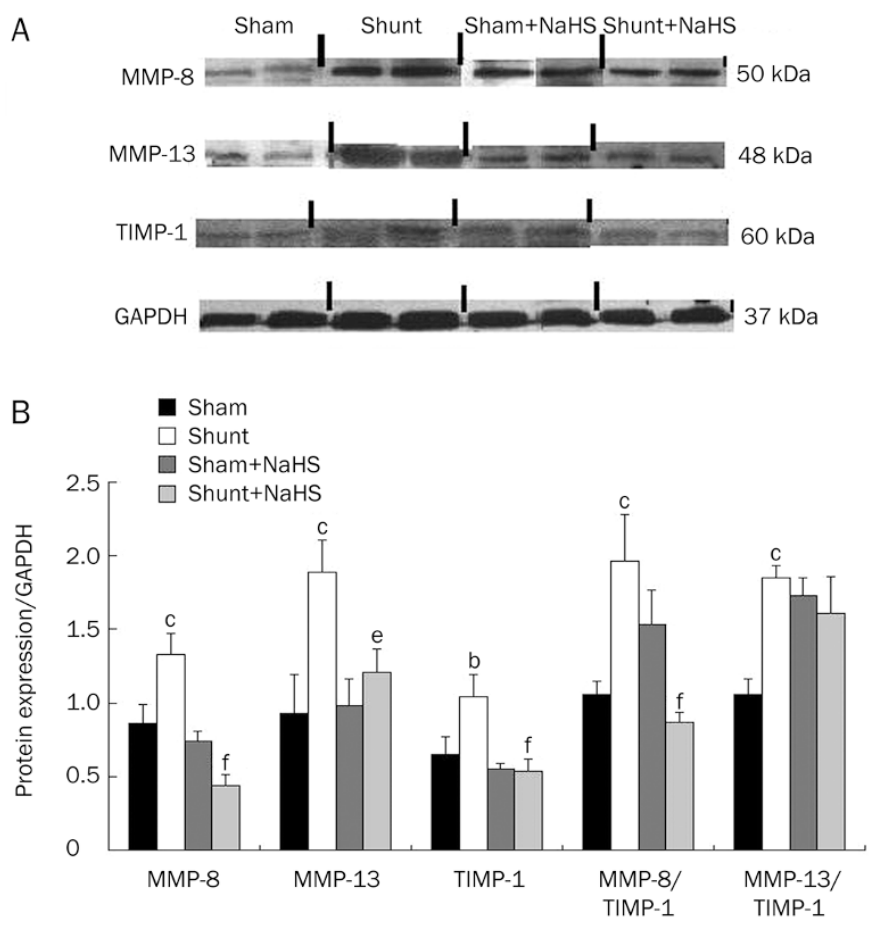

Figure 2. Cardiac protein expression in the left ventricular (LV) using Western blotting. (A) SDS/PAGE analysis shows MMP-8, MMP-13, and TIMP-1 protein levels in the LV of rats, (B) and changes in MMP-8, MMP-13, TIMP-1, MMP-8/TIMP-1, and MMP-13/TIMP-1 protein expression. Mean \pm SEM. $n=6-8$. ${ }^{b} P<0.05,{ }^{c} P<0.01$ versus the sham group. ${ }^{e} P<0.05,{ }^{f} P<0.01$ versus the shunt group. MMP, matrix metalloproteinase; TIMP, tissue inhibitor of metalloproteinase; NaHS, sodium hydrosulfide; GAPDH, glyceraldehyde-3-phosphate dehydrogenase.

\section{Discussion}

CHD is one of the most common human birth defects, with an incidence ranging between 6 and 8 per 1000 live births ${ }^{[24]}$. CHF is a common complication of left-to-right shunt CHD, and ventricular remodeling is an important pathophysiological basis of volume overload-induced CHF. Therefore, it is important to determine the mechanism responsible for volume overloadinduced ventricular remodeling. In this study, we created a volume overload rat model by abdominal artery-inferior vena cava puncture $^{[25]}$. The Qp/Qs ratios in the remaining shunt rats were close to 2.0, suggesting successful creation of shunts and sustained volume overload.

Recent experimental studies showed that endogenous

Table 3. MMP-8, MMP-13, and TIMP-1 mRNA expression in the left ventricular $\left(2^{-\triangle \Delta C T}\right)$. Mean \pm SEM. ${ }^{b} P<0.05$, ${ }^{\mathrm{c}} P<0.01$ compared with the sham group. ${ }^{e} P<0.05,{ }^{f} P<0.01$ compared with the shunt group. MMP, matrix metalloproteinase; TIMP, tissue inhibitor of metalloproteinase; NaHS, sodium hydrosulfide.

\begin{tabular}{|c|c|c|c|c|c|c|}
\hline Group & $n$ & MMP-8 & MMP-13 & TIMP-1 & MMP-8/TIMP-1 & MMP-13/TIMP-1 \\
\hline Sham & 8 & $1.02 \pm 0.07$ & $1.99 \pm 0.24$ & $1.38 \pm 0.05$ & $0.91 \pm 0.01$ & $1.32 \pm 0.13$ \\
\hline Sham+NaHS & 6 & $0.44 \pm 0.04$ & $1.28 \pm 0.18$ & $1.28 \pm 0.05$ & $0.40 \pm 0.08$ & $2.06 \pm 0.50$ \\
\hline Shunt+NaHS & 8 & $1.54 \pm 0.04$ & $2.56 \pm 0.13^{f}$ & $1.75 \pm 0.10^{\mathrm{e}}$ & $0.79 \pm 0.13$ & $1.66 \pm 0.14^{e}$ \\
\hline
\end{tabular}



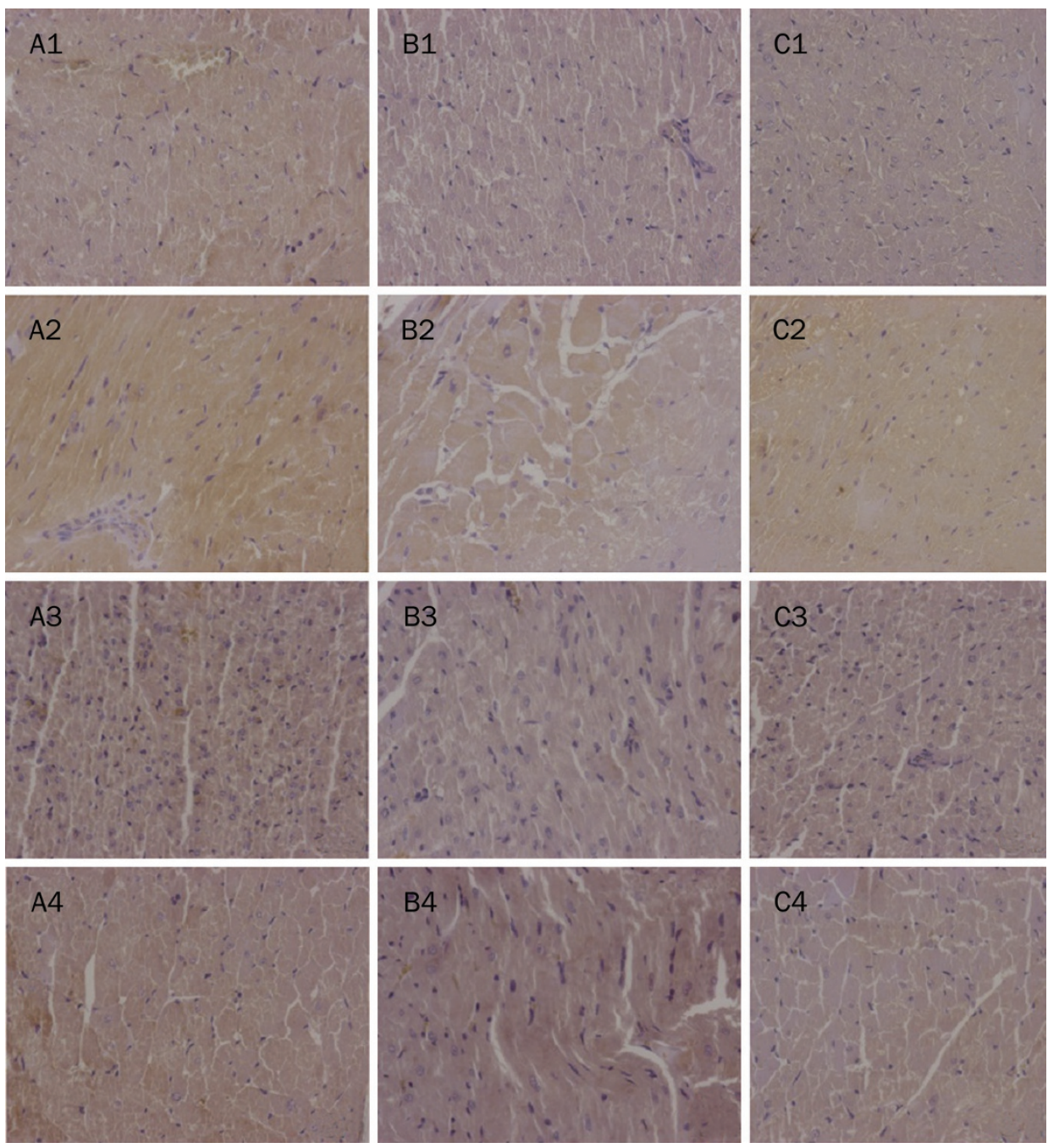

Figure 3. Representative immunohistochemical analysis of cardiac matrix metalloproteinase-8 (MMP-8), MMP-13, and tissue inhibitor of metalloproteinase-1 (TIMP-1) expression in the left ventricular of rats. The cytoplasm of myocardial cells is uniformly distributed, with sparse light brown particles in the sham and sham+sodium hydrosulfide (NaHS) groups. In the shunt group, dense, irregularly distributed, brown granules can be observed in the cytoplasm of myocardial cells. Myocardial cytoplasmic brown granules were significantly decreased in the shunt+NaHS group compared to the shunt group. (original magnification 400×). (A) MMP-8; (B) MMP-13; (C) TIMP-1. A1-C1, sham group; A2-C2, shunt group; A3-C3, sham+NaHS group; A4-C4, shunt+NaHS group.

$\mathrm{H}_{2} \mathrm{~S}$ synthesis in the heart was lowered in an arterio-venous fistula-induced CHF model ${ }^{[3]}$. Shi et $a l^{[26]}$ reported that chronic treatments with NaHS were effective at doses of 10,30 , and $90 \mu \mathrm{mol} \cdot \mathrm{kg}^{-1} \cdot \mathrm{d}^{-1}$ for $3 \mathrm{mo}$ for the inhibition of perivascular and interstitial fibrosis in spontaneously hypertensive rats (SHR). Chronic treatments with NaHS at doses of 30 and 90 $\mu \mathrm{mol} \cdot \mathrm{kg}^{-1} \cdot \mathrm{d}^{-1}$ significantly reduced left-ventricular end-diastolic and -systolic posterior wall thickness (LVPWd and LVPWs) in SHR, but NaHS treatment showed no significant effect on LV chamber size as indicated by left-ventricular end-diastolic and -systolic dimensions (LVDD and LVSD). Treatment with NaHS $\left(10,30\right.$, and $\left.90 \mu \mathrm{mol} \cdot \mathrm{kg}^{-1} \cdot \mathrm{d}^{-1}\right)$ had no effect on indexes of LV systolic functional parameters in SHR.

In the present study, we intraperitoneally injected $\mathrm{NaHS}$ at $56 \mu \mathrm{mol} \cdot \mathrm{kg}^{-1} \cdot \mathrm{d}^{-1}$ for 8 weeks as previously described ${ }^{[20]}$. The significant changes in LVSP, LVEDP, and $\mathrm{LV} \pm \mathrm{d} p / \mathrm{d} t_{\max }$ indicated that $\mathrm{H}_{2} \mathrm{~S}$ could improve cardiac function of volume overload. Furthermore, the results indicate that long-term treatments with NaHS did not affect the left ventricular hemodynamic parameters in sham-operated rats, although it showed a significant pharmacological effect in pathological conditions (such as $\mathrm{CHF}$ ). This finding indicates that $\mathrm{H}_{2} \mathrm{~S}$ may protect the heart from volume overload; however, the underlying mechanism is unclear.

Fibrillar collagens are an important component of the ECM, with type I representing approximately $85 \%$. The present study showed that left ventricular myocardial tissue hydroxyproline, a sensitive biochemical marker that reacts to collagen fiber changes, and collagen type I increased significantly in rats receiving a shunt operation, suggesting ventricular 
A
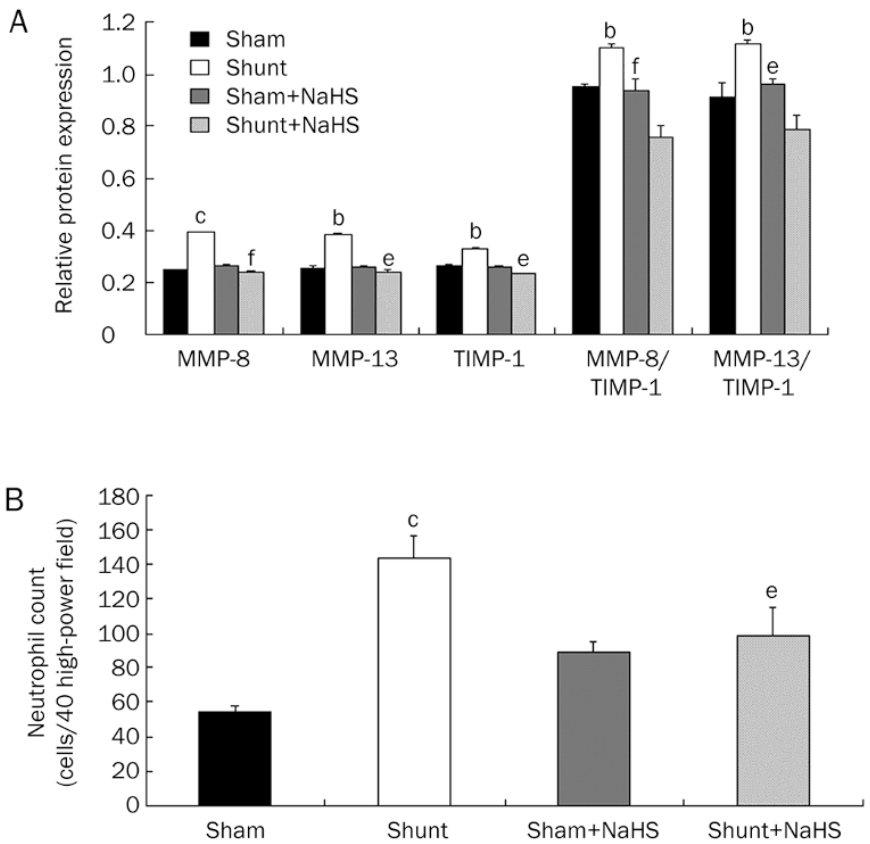

Figure 4. Immunohistochemical analysis of cardiac protein expression and neutrophil accumulation in the left ventricle. (A) Changes in MMP-8, MMP-13, TIMP-1, MMP-8/TIMP-1, and MMP-13/TIMP-1 protein expression. (B) Neutrophil accumulation. Mean \pm SEM. $n=6-8$. ${ }^{\mathrm{b}} P<0.05$, ${ }^{\mathrm{c}} P<0.01$ versus the sham group. ${ }^{\mathrm{e}} P<0.05,{ }^{\mathrm{f}} P<0.01$ versus the shunt group. MMP, matrix metalloproteinase; TIMP, tissue inhibitor of metalloproteinase; NaHS, sodium hydrosulfide; IOD, integral optical density.

remodeling by volume overload. However, after being treated with NaHS, left ventricular remodeling was ameliorated. Activation of collagenase can degrade matrix collagen and destroy the collagen network structure ${ }^{[27]}$. The MMP species primarily responsible for fibrillar collagen degradation are the collagenases MMP-1, MMP-13, and MMP-8.

In the present study, after 8 weeks of shunting, MMP- 8 and MMP-13 mRNA expression in the LV increased in the shunt group. A clinical observational study has shown that the plasma levels of MMP-2 in patients with CHF is significantly higher in comparison to normal control subjects, suggesting that the increased plasma MMP levels may correlate with $\mathrm{CHF}^{[28]}$, in agreement with our findings. After being treated with NaHS, MMP-13 mRNA expression was significantly decreased. MMP-8 mRNA expression was unchanged. We also found that protein MMP-8 and MMP-13 expression was significantly increased in the shunt group. After treating the shunt group with NaHS, protein MMP-8 and MMP-13 expression significantly decreased. With the administration of NaHS in the sham group, no difference in MMP-13, and TIMP-1 expression was observed. These findings demonstrated that $\mathrm{H}_{2} \mathrm{~S}$ regulated MMP-8 and MMP-13 at the gene and protein level in volume overload-induced ventricular remodeling, mainly playing a role in pathological conditions.

TIMPs are specific inhibitors of MMPs that participate in regulating the local activity of MMPs in tissues. Our study showed that after 8 weeks of shunting, TIMP-1 mRNA expression was significantly greater. After being treated with NaHS in shunt group, TIMP-1 mRNA expression was significantly reduced. Furthermore, we found similar changes in TIMP-1 protein expression levels, which is consistent with a previous report ${ }^{[29]}$. When NaHS was administered to the sham group, no difference in TIMP-1 expression was observed. These findings suggested that $\mathrm{H}_{2} \mathrm{~S}$ regulated TIMP- 1 at the gene and protein level in volume overload-induced ventricular remodeling, mainly playing a role in pathological conditions.

Previous studies have reported that TIMP-1 forms a 1:1 stoichiometric complex with MMPs. The MMP/TIMP complex forms a stable noncovalent moiety that is not completely dissociated after SDS-PAGE. The polyclonal antiserum used in the present study recognized TIMPs in the unbound form, as well as when complexed to MMP. Therefore, the $60 \mathrm{kDa}$ molecular weight band observed in the western blot of TIMP may represent a TIMP/MMP complex. Our study demonstrated that after 8 weeks of shunting, the ratios of MMP-8/ TIMP-1 and MMP-13/TIMP-1 were increased. These results suggested that after the shunt operation, MMP-8 and MMP-13 expression was increased more significantly than that of TIMP-1. Although TIMP-1 levels increased, they were insufficient to inhibit the activity of MMPs and modify ventricular remodeling.

After being treated with NaHS in shunt group, the ratio of MMPs/TIMP-1 mRNA decreased. This finding suggests that the effect of $\mathrm{H}_{2} \mathrm{~S}$ on MMPs is more significant than that of TIMP-1. Changes in MMPs are more rapid than those in TIMP; therefore, $\mathrm{H}_{2} \mathrm{~S}$ can rapidly halt the degradation of myocardial interstitial collagen, restoring normal ECM structure. MMP-8 is mainly synthesized and released by inflammatory cells; therefore, it may be more vulnerable to anti-inflammatory effects of $\mathrm{H}_{2} \mathrm{~S}$. The mechanism for the dissociation of the MMP-8 transcript and protein expression remains unclear. Post-transcriptional regulation, including altered efficiency of translation, decreased mRNA half-life, or increased protein degradation could account for the difference.

The mechanisms responsible for regulating MMP/TIMP by $\mathrm{H}_{2} \mathrm{~S}$ in volume overload-induced ventricular remodeling remain undefined. Three potential factors involved in the increase in MMP mRNA levels in heart failure are cytokines, inflammatory cell infiltration, and cytoskeletal remodeling. A variety of cytokines ( $e g$, tumor necrosis factor- $\alpha$ and interleukin-1 $\beta$ ) have been shown to regulate the expression of MMPs and TIMPs ${ }^{[30-32]}$. The increase in MMP-8, MMP-13, and TIMP-1 observed in the current study after shunt operation may have been caused by inflammatory cells, which were increased in ventricular remodeling.

Recently, $\mathrm{H}_{2} \mathrm{~S}$ donors were reported to induce neutrophil apoptosis and to suppress expression of some leukocytes, endothelial adhesion molecules and proinflammatory cytokines. Our study also demonstrated that the shunt operation caused significant increases in the accumulation of neutrophils, and these effects were significantly attenuated by NaHS. $\mathrm{H}_{2} \mathrm{~S}$ most likely regulates MMP/TIMP changes through these anti- 
inflammatory effects. In addition, Mossiat et al indicated that oxidative stress is an important mediator for the progression of heart failure ${ }^{[33]}$. Two studies reported that at low levels, $\mathrm{H}_{2} \mathrm{~S}$ defends organs from several pathophysiological conditions, such as oxidative stress and ischemia-reperfusion ${ }^{[34,35]}$. The antioxidant property of $\mathrm{H}_{2} \mathrm{~S}$ was partly mediated by increasing intracellular catalase (CAT) and superoxide dismutase (SOD), which are the most efficient enzymatic antioxidants ${ }^{[36,37]}$. Thus, $\mathrm{H}_{2} \mathrm{~S}$ supplementation regulates MMPs, in part, through its antioxidant properties. However, the specific mechanism of this process requires further study. Additionally, in this study, the protein and mRNA expression of MMP-8, MMP-13, and TIMP-1 were only measured with one concentration of NaHS. Additional concentrations will need to be studied in future experiments.

In conclusion, the present study demonstrated that $\mathrm{H}_{2} \mathrm{~S}$ downregulated protein and mRNA expression of MMP-8, MMP-13, and TIMP-1 in rats with volume overload, and this effect might be involved in the amelioration of ventricular structural remodeling and cardiac function.

\section{Acknowledgements}

The work was supported by the National Natural Science Foundation of China (№ 30872787), Beijing Outstanding Talents Training Program (20081D0303200107) and Science Foundation for High-Level Medical Talents of Beijing Health System (2011-3-067).

\section{Author contribution}

Xiao-hui LI and Ting ZHANG designed the study; Chao-ying ZHANG conducted the experiments; Jin FU and Xiao-dai CUI supplied critical reagents and equipments; Chao-ying ZHANG and Xiao-hui LI wrote the manuscript.

\section{References}

1 Masutani S, Taketazu M, Ishido H, Iwamoto Y, Yoshiba S, Matsunaga T, et al. Effects of age on hemodynamic changes after transcatheter closure of atrial septal defect: importance of ventricular diastolic function. Heart Vessels 2012; 27: 71-8.

2 Liu YH, Yan CD, Bian JS. Hydrogen sulfide: a novel signaling molecule in the vascular system. J Cardiovasc Pharmacol 2011; 58: 560-9.

3 Liu YH, Lu M, Hu LF, Wong PT, Webb GD, Bian JS. Hydrogen sulfide in the mammalian cardiovascular system. Antioxid Redox Signal 2012; 17: 141-85.

4 Muellner MK, Schreier SM, Laggner H, Hermann M, Esterbauer H, Exner $M$, et al. Hydrogen sulfide destroys lipid hydroperoxides in oxidized LDL. Biochem J 2009; 420: 277-81.

5 Ji Y, Pang QF, Xu G, Wang L, Wang JK, Zeng YM. Exogenous hydrogen sulfide postconditioning protects isolated rat hearts against ischemiareperfusion injury. Eur J Pharmacol 2008; 587: 1-7.

6 Su YW, Ding YG, Zhang CY, Zhang QY, Qi JG, Tang CS, et al. Changes hydrogen sulfide in plasma of children with congenital heart disease. J Appl Clin Pediatr 2005; 7: 632-4. Chinese.

7 Johansen D, Ytrehus K, Baxter GF. Exogenous hydrogen sulfide $\left(\mathrm{H}_{2} \mathrm{~S}\right)$ protects against regional myocardial ischemia-reperfusion injury evidence for a role of K-ATP channels. Basic Res Cardiol 2006; 101 : 53-60.

8 Zhu YZ, Wang ZJ, Ho P, Loke YY, Zhu YC, Huang SH, et al. Hydrogen sulfide and its possible roles in myocardial ischemia in experimental rats. J Appl Physiol 2007; 102: 261-8.

9 Li XH, Zhang CY, Zhang T. Sodium hydrosulfide improves cardiac functions and structures in rats with chronic heart failure. Zhonghua Yi Xue Za Zhi 2011; 91: 3044-9. Chinese.

10 Visse R, Nagase $\mathrm{H}$. Matrix metalloproteinases and tissue inhibitors of metalloproteinases: structure, function, and biochemistry. Circ Res 2003; 92: 827-39.

11 Gunja-Smith Z, Morales AR, Romanelli R, Woessner JF. Remodeling of human myocardial collagen in idiopathic dilated cardiomyopathy. Role of metalloproteinases and pyridinoline cross-links. Am J Pathol 1996; 148: 1639-48.

12 Spinale FG, Coker ML, Bond BR, Zellner JL. Myocardial matrix degradation and metalloproteinase activation in the failing heart: a potential therapeutic target. Cardiovas Res 2000; 46: 225-38.

13 Peterson JT, Hallak H, Johnson L, Li H, O'Brien PM, Sliskovic DR, et al. Matrix metalloproteinase inhibition attenuates left ventricular remodeling and dysfunction in a rat model of progressive heart failure. Circulation 2001; 103: 2303-9.

14 Brew K, Nagase H. The tissue inhibitors of metalloproteinases (TIMPs): An ancient family with structural and functional diversity. Biochim Biophys Acta 2010; 1803: 55-71.

15 Creemers EE, Davis JN, Parkhurst AM, Leenders P, Dowdy KB, Hapke $E$, et al. Deficiency of TIMP-1 exacerbates LV remodeling after myocardial infarction in mice. Am J Physiol Heart Circ Physiol 2003; 284: H364-71.

16 Ikonomidis JS, Hendrick JW, Parkhurst AM, Herron AR, Escobar $P G$, Dowdy KB, et al. Accelerated LV remodeling after myocardial infarction in TIMP-1-deficient mice: effects of exogenous MMP inhibition. Am J Physiol Heart Circ Physiol 2005; 288: H149-58.

17 Chancey AL, Brower GL, Peterson JT, Janicki JS. Effects of matrix metalloproteinase inhibition on ventricular remodeling due to volume overload. Circulation 2002; 105: 1983-8.

18 Thomas CV, Coker ML, Zellner JL, Handy JR, Crumbley AJ 3rd, Spinale FG. Increased matrix metalloproteinase activity and selective upregulation in LV myocardium from patients with end-stage dilated cardiomyopathy. Circulation 1998; 97: 1708-15.

19 Li H, Simon H, Bocan TM, Peterson JT. MMP/TIMP expression in spontaneously hypertensive heart failure rats: the effect of ACE- and MMP-inhibition. Cardiovasc Res 2000; 46: 298-306.

20 Sivasubramanian N, Coker ML, Kurrelmeyer KM, MacLellan WR, DeMayo FJ, Spinale FG, et al. Left ventricular remodeling in transgenic mice with cardiac restricted overexpression of tumor necrosis factor. Circulation 2001; 104: 826-31.

21 Ocampo C, Ingram P, Ilbawi M, Arcilla R, Gupta M. Revisiting the surgical creation of volume load by aorto-caval shunt in rats. Mol Cell Biochem 2003; 251: 139-43.

22 Yan H, Du J, Tang C. The possible role of hydrogen sulfide on the pathogenesis of spontaneous hypertension in rats. Biochem Biophys Res Commun 2004; 313: 22-7.

23 Wang XL, Wang Q, Wei G, Zhu YZ. Hydrogen sulfide attenuates cardiac dysfunction in a rat model of heart failure: a mechanism through cardiac mitochondrial protection. Biosci Rep 2011; 31: 87-98.

24 Sadowski SL. Congenital cardiac disease in the newborn infant: past, present, and future. Crit Care Nurs Clin North Am 2009; 21: 37-48.

25 Wang X, Ren B, Liu S, Sentex E, Tappia PS, Dhalla NS. Characterization of cardiac hypertrophy and heart failure due to volume overload in the rat. J Appl Physiol 2003; 94: 752-63.

26 Shi YX, Chen Y, Zhu YZ, Huang GY, Moore PK, Huang SH, et al. Chronic sodium hydrosulfide treatment decreases medial thickening of intramyocardial coronary arterioles, interstitial fibrosis, and ROS 
production in spontaneously hypertensive rats. Am J Physiol Heart Circ Physiol 2007; 293: H2093-100.

27 Kim HE, Dalal SS, Young E, Legato MJ, Weisfeldt ML, D'Armiento J. Disruption of the myocardial extracellular matrix leads to cardiac dysfunction. J Clin Invest 2000; 106: 857-66.

28 George J, Patal S, Wexler D, Roth A, Sheps D, Keren G. Circulating matrix metalloproteinase-2 but not matrix metalloproteinase-3, matrix metalloproteinase-9, or tissue inhibitor of metalloproteinase-1 predicts outcome in patients with congestive heart failure. Am Heart J 2005; 150: 484-7.

29 Mishra PK, Tyagi N, Sen U, Givvimani S, Tyagi SC. $\mathrm{H}_{2} \mathrm{~S}$ ameliorates oxidative and proteolytic stresses and protects the heart against adverse remodeling in chronic heart failure. Am J Physiol Heart Circ Physiol 2010; 298: H451-6.

30 Vincenti MP, Coon Cl, Brinckerhoff CE. Nuclear factor kappaB/p50 activates an element in the distal matrix metalloproteinase 1 promoter in interleukin-1beta-stimulated synovial fibroblasts. Arthritis Rheum 1998; 41: 1987-94.

31 Li YY, McTiernan CF, Feldman AM. Proinflammatory cytokines regulate tissue inhibitors of metalloproteinases and disintegrin metalloprotei- nase in cardiac cells. Cardiovasc Res 1999; 42: 162-72.

32 Yamamoto Y, Osanai T, Nishizaki F, Sukekawa T, Izumiyama K, Sagara S, et al. Matrix metalloprotein-9 activation under cell-to-cell interaction between endothelial cells and monocytes: possible role of hypoxia and tumor necrosis factor- $\alpha$. Heart Vessels 2012; 27: 624-33.

33 Mossiat C, Demougeot C, Priqent-Tessier A, Bertrand N, Garnier P, Beley A, et al. Effects of iNOS-related NO on hearts exposed to liposoluble iron. Free Radic Res 2003; 37: 749-56.

34 Kimura $\mathrm{Y}$, Kimura $\mathrm{H}$. Hydrogen sulfide protects neurons from oxidative stress. FASEB J 2004; 18: 1165-7.

35 Yonezawa D, Sekiguchi F, Miyamoto M, Taniguchi E, Honjo M, Masuko T, et al. A protective role of hydrogen sulfide against oxidative stress in rat gastric mucosal epithelium. Toxicology 2007; 241: 11-8.

36 Sen U, Basu P, Abe OA, Giwimani S, Tyagi N, Metreveli N, et al. Hydrogen sulfide ameliorates hyperhomocysteinemia-associated chronic renal failure. Am J Physiol Renal Physiol 2009; 297: F410-9.

37 Bagatini MD, Martins CC, Battisti V, Gasparetto D, da Rosa CS, Spanevello RM, et al. Oxidative stress versus antioxidant defenses in patients with acute myocardial infarction. Heart Vessels 2011; 26 : 55-63. 